\title{
Necrosis- and apoptosis-related Met cleavages have divergent functional consequences
}

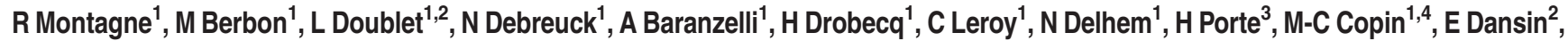 \\ A Furlan ${ }^{1}$ and $D$ Tulasne ${ }^{*, 1}$
}

Upon activation by its ligand hepatocyte growth factor/scatter factor, the receptor tyrosine kinase Met promotes survival, proliferation, and migration of epithelial cells during embryogenesis. Deregulated Met signaling can also promote cancer progression and metastasis. Met belongs to the functional family of dependence receptors whose activity switches from pro-survival to pro-apoptotic during apoptosis upon caspase cleavage. Although apoptosis resistance is a hallmark of cancer cells, some remain sensitive to other cell death processes, including necrosis induced by calcium stress. The role and fate of Met during necrotic cell death are unknown. Following treatment with calcium ionophores, cell lines and primary cells undergo necrosis, and the full-length Met receptor is efficiently degraded. This degradation is achieved by double cleavage of Met in its extracellular domain by a metalloprotease of the A disintegrin and metalloproteinase (ADAM) family and in its intracellular domain by calpains (calcium-dependent proteases). These cleavages separate the Met extracellular region from its kinase domain, thus preventing Met activity and its potential pro-survival activity. Although the intracellular fragment is very similar to the fragment generated by caspases, it displays no pro-apoptotic property, likely because of the presence of the last few amino acids of Met, known to inhibit this pro-apoptotic function. The fragments identified here are observed in lung tumors overexpressing the Met receptor, along with fragments previously identified, suggesting that proteolytic cleavages of Met are involved in its degradation in tumor tissues. Thus, Met is a modulator of necrosis, able to protect cells when activated by its ligand but efficiently degraded by proteolysis when this process is engaged.

Cell Death and Disease (2015) 6, e1769; doi:10.1038/cddis.2015.132; published online 21 May 2015

Met is a receptor tyrosine kinase expressed predominantly by epithelial cells and activated by its stromal ligand, hepatocyte growth factor/scatter factor (HGF/SF). Met activation stimulates a biological program called invasive growth, ${ }^{1}$ involving survival, proliferation, invasion, and morphogenesis of epithelial cells. Ligand-stimulated Met acts, furthermore, as an angiogenic and neurotrophic factor. ${ }^{2,3}$ HGF/SF and Met are essential to several steps of embryogenesis, experiments on transgenic mice having shown that they are necessary for formation of the placenta, liver, limb muscle, neurons, and lung airspace..$^{4-8}$ In adults, HGF/SF and Met promote regeneration of several organs, including the liver, kidneys, and thymus. ${ }^{9-13}$

Aberrant Met and HGF/SF signaling contributes to promoting tumorigenesis and metastasis (for review see Furlan et al.). ${ }^{14} \mathrm{~A}$ direct link between Met and cancer has been evidenced by observation of Met germinal mutations linked to hereditary papillary renal carcinoma. ${ }^{15}$ Met and/or HGF/SF are/is also overexpressed in several human cancers. ${ }^{16}$ Given its important oncogenic activity, Met is the target of many therapeutic agents currently under clinical investigation. ${ }^{17}$

Downregulation of Met following its activation by HGF/SF is an important negative regulatory mechanism preventing receptor overactivation. We have previously shown that Met expression and activity are also controlled by proteolytic cleavages. Under steady-state conditions, Met is processed by PS-RIP (presenilin-regulated intramembrane proteolysis). ${ }^{18,19}$ This process involves cleavage of Met within its extracellular juxtamembrane domain by $\mathrm{A}$ disintegrin and metalloproteinase (ADAM)- $10,{ }^{20}$ generating a soluble $\mathrm{N}$-terminal fragment (Met-NTF), which is released into the extracellular space, and a membrane-anchored C-terminal Met fragment (Met-CTF). The latter is in turn efficiently degraded by the lysosome and by further $\gamma$-secretase cleavages.

${ }^{1}$ CNRS UMR 8161, Institut de Biologie de Lille-Institut Pasteur de Lille, Université de Lille, SIRIC ONCOLille, Lille 59021, France; ${ }^{2}$ Département de Cancérologie Générale, CLCC Oscar Lambret, Université de Lille, 3 rue Fréderic Combemale, Lille 59020, France; ${ }^{3}$ Service de Chirurgie Thoracique, Centre Hospitalier Régional Universitaire de Lille, Université de Lille, Lille, France and ${ }^{4}$ Institut de Pathologie, Centre Hospitalier Régional Universitaire de Lille, Université de Lille, Avenue Oscar Lambret, Lille 59037, France

${ }^{*}$ Corresponding author: D Tulasne, CNRS UMR 8161, Institut de Biologie de Lille-Institut Pasteur de Lille, Université de Lille, SIRIC ONCOLille, 1 Rue Pr Calmette, BP447, 59021 Lille, France. Tel: +33 3208712 57; Fax: +33 32087 11 11; E-mail: david.tulasne@ibl.cnrs.fr

Abbreviations: ADAM, A disintegrin and metalloproteinase; ALLN, N-Acetyl-L-leucyl-L-leucyl-L-norleucinal; ATP, adenosine triphosphate; Bak, Bcl-2 antagonist/killer Bax, Bcl-2 associated X-protein; ERK, extracellular signal-regulated kinase; FBS, fetal bovine serum; GAPDH, glyceralehyde-3-phosphate dehydrogenase; Grb2, growth factor receptor-bound protein 2; HGF/SF, hepatocyte growth factor/scatter factor; IHC, immunohistochemistry; Met-CTF, Met C-terminal fragment; Met-NTF, Met N-terminal fragment; NSCLC, non-small-cell lung cancer; PARP, poly(ADP-ribose) polymerase; PI, propidium iodide; PS-RIP, presenilin-regulated intramembrane proteolysis QVD-OPh, $N$-(2-quinolyl)-L-valyl-L-aspartyl-(2,6-difluorophenoxy) methylketone; RNA, ribonucleic acid; siRNA, small interfering RNA; TAPI, TNF- $\alpha$ processing inhibitor TRK, tropomyosine receptor kinase; Z-FA-FMK, Z-Phe-Ala fluoromethyl ketone

Received 19.2.15; revised 09.4.15; accepted 14.4.15; Edited by R Johnstone 
Constitutive degradation of the Met receptor by PS-RIP contributes to regulating its half-life.

Under apoptotic conditions, Met is cleaved by caspases ${ }^{21}$ within its C-terminal tail and its intracellular juxtamembrane domain. These cleavages remove the C-terminal tail of Met and separate the extracellular ligand-binding domain from the intracellular kinase domain. The generated 40-kDa intracellular fragment, previously called 'p40Met' and here called p40Met ${ }^{\text {caspase }}$, can increase cell death by promoting mitochondrial permeabilization. ${ }^{22,23}$ Removal of the C-terminal tail of Met is required for the efficient pro-apoptotic action of the fragment. This pro-apoptotic function of Met makes it a member of the dependence receptor family. ${ }^{24}$ Met cleavages are illustrated in Figure 6a.

Although the mechanisms underlying apoptosis have been studied extensively, necrosis has only recently been described as a regulated cell death mechanism. ${ }^{25}$ Necrosis is an adenosine triphosphate (ATP)-independent cell death mechanism featuring early plasma membrane and organelle disruption. Many pathways can lead to cell necrosis, including calcium overload. This type of cell stress has been amply described in the nervous system, where an increase in intracellular calcium results in neuronal injury and neurodegenerative diseases. In many other cell types, calcium ionophores such as ionomycin can induce rapid necrosis. An increase in intracellular calcium triggers activation of several proteases, including calpains and cathepsins. ${ }^{26-28}$ Calpains are calcium-dependent proteases capable of cleaving multiple substrates and involved in regulating various cellular processes, including migration, autophagy, apoptosis, and necrosis. Interestingly, the effector role of calpains during necrosis is reminiscent of the function of caspases during apoptosis. Caspases are directly involved in morphological changes observed during apoptosis, while calpains can cleave cytoskeletal proteins such as spectrin and tubulin, thus favoring dismantling of cell structure during necrosis. ${ }^{29-31}$

Although apoptosis resistance is a hallmark of many cancer cells, ${ }^{32}$ some such cells remain sensitive to other cell death processes, including necrosis. ${ }^{33}$ Thus, a better understanding of the mechanisms underlying necrosis is important, as it could help to elaborate novel therapeutic strategies. Here we show that calcium stress induced by calcium ionophores triggers Met degradation during necrotic cell death. This loss of Met receptor occurs early during the process and is mediated by Met cleavages: by calpains in its intracellular part and by metalloproteases in its extracellular part. These cleavages generate an extracellular fragment and an intracellular fragment with a molecular weight close to that of p40Met ${ }^{\text {caspase. }}$.

\section{Results}

Calcium-stress-induced necrosis triggers Met degradation. In order to investigate the fate of Met during necrosis, we administered different pharmacological drugs known to induce either necrosis or apoptosis. Treatment of MCF-10A epithelial cells with staurosporine triggered cell death with the distinctive features of apoptosis, including cleavage of the caspase substrate poly(ADP-ribose) polymerase (PARP),
Annexin V staining, along with degradation of full-length Met, and production of the pro-apoptotic fragment p40Met ${ }^{\text {caspase }}$ (Figures 1a and b). In contrast, treatment with the calcium ionophore ionomycin induced, after a few hours, cell death without PARP cleavage or any significant phosphatidylserine externalization. Instead, the cells displayed sustained propidium iodide $(\mathrm{PI})$ staining, suggesting early plasma membrane disruption consistent with known necrotic cell death induced by calcium ionophores (Figure 1b). Ionomycin treatment also induced early degradation of Met and production of a fragment of $\sim 40 \mathrm{kDa}$, only slightly different in molecular weight from p40Met ${ }^{\text {caspase }}$ (Figure 1a). Faint bands were also observed $\sim 55 \mathrm{kDa}$, reminiscent of the Met-CTF fragments generated by PS-RIP. ${ }^{18,19}$ lonomycin treatment was found to cause similar Met degradation and $40-\mathrm{kDa}$ fragment generation in MDAMB231 breast cancer cells and Met-overexpressing GTL-16 gastric cancer cells (Supplementary Figures S1A and B), and also in primary cultures of mouse mammary epithelial cells and in human primary hepatocytes (Figures $1 \mathrm{c}$ and d). Generation of the $40-\mathrm{kDa}$ fragment was observed from $100 \mathrm{nM}$ ionomycin upward, with maximal generation at $1 \mu \mathrm{M}$, associated with degradation of full-length Met (Supplementary Figure S1C). Ionomycin treatment in calcium-free medium failed to induce Met degradation (Supplementary Figure S1D), while treatment of MCF-10A cells with A23187, another calcium ionophore, caused a decrease in full-length Met and generation of the 40-kDa fragment (Supplementary Figure S1E).

During calcium-induced necrosis, consistently with the observed efficient degradation of Met, HGF/SF stimulation of ionomycin-pretreated cells failed to activate Met and its downstream signaling proteins ERK (extracellular signalregulated kinase) and $\mathrm{AKT}$ (Figure $2 \mathrm{a}$ ). It is worth noting that ionomycin treatment did cause ERK activation, but that HGF/SF was unable to induce its further stimulation. To evaluate the survival response potentially induced by Met, HGF/SF-pretreated cells were incubated with ionomycin. HGF/SF was found to reduce Met degradation and generation of the $40-\mathrm{kDa}$ fragment, concomitantly with a decrease in $\mathrm{PI}$ staining (Figures $2 \mathrm{~b}$ and $\mathrm{c}$ ).

Calpains perform intracellular Met cleavage during necrosis. To see whether the $40-\mathrm{kDa}$ fragment observed during calcium stress is generated by proteolytic cleavage, we incubated epithelial cells with various protease inhibitors before ionomycin treatment. In contrast to caspase and cathepsin inhibitors (Figure 3a), the calpain inhibitor calpeptin was found to decrease production of the $40-\mathrm{kDa}$ fragment in a dose-dependent manner (Figures $3 a$ and $b$ ). Activation of calpains during calcium stress was confirmed by calpain 1 autolysis, detected by generation of a cleaved form (Figures $3 c$ and $d$ and Supplementary Figure S1C). Met-receptortargeting ribonucleic acid (RNA) interference led to loss of the calcium stress fragment, confirming that it is a fragment of the Met receptor. RNA interference targeting calpains 1 and 2 (the two best-characterized ubiquitous calpain isoforms) decreased (but did not totally prevent) production of the calcium stress fragment, indicating an involvement of these two proteases (Figure 3d). Neither calpain inhibitor treatment nor RNA interference targeting calpains 1 and 2 was found to restore detection of full-length Met. 
a

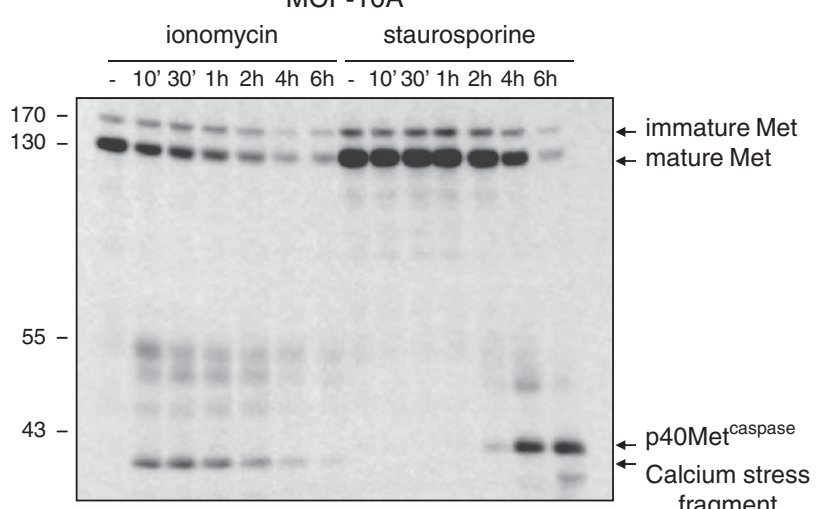

WB Met

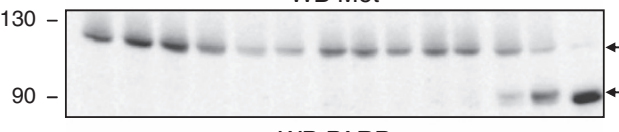

fragment

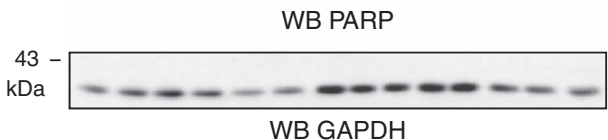

PARP cleaved PARP

c

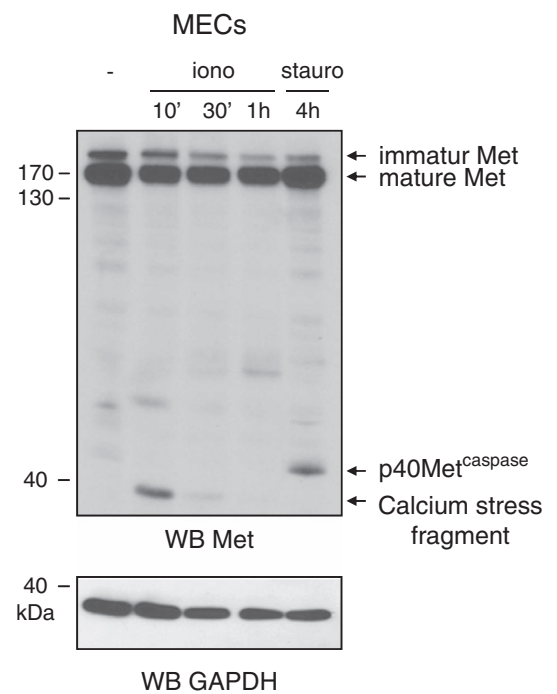

d b
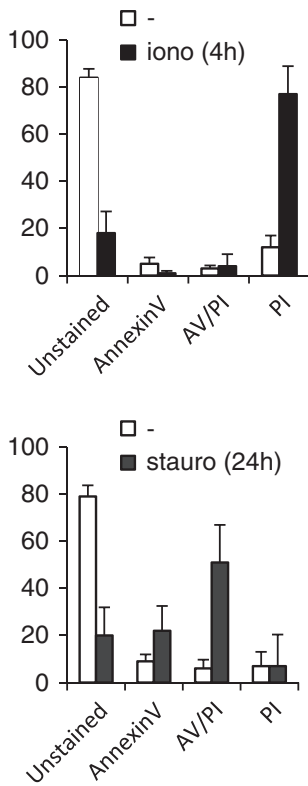
Primary human hepatocytes

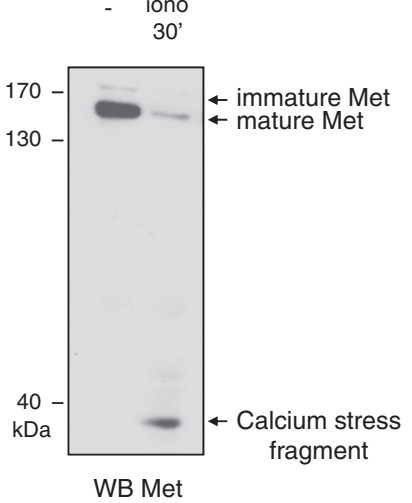

Fonomycin induces necrotic cell death and generation of a 40-kDa Met fragment. (a) MCF-10A cells were grown for $24 \mathrm{~h}$, serum starved overnight, and treated with $1 \mu \mathrm{M}$ ionomycin (iono) or $1 \mu \mathrm{M}$ staurosporine (stauro) for the indicated time. (b) MCF-10 A cells were treated with $1 \mu \mathrm{M}$ ionomycin or $1 \mu \mathrm{M}$ staurosporine then stained with Annexin V-fluorescein isothiocyanate (FITC) and PI. Percentages of unstained cells and of cells stained with Annexin V, PI, or both (AV/PI) are shown. Mouse mammary epithelial cells (MECs) (c) or human primary hepatocytes (d) were treated with $1 \mu \mathrm{M}$ ionomycin or $1 \mu \mathrm{M}$ staurosporine for the indicated time. (a, $\mathbf{c}$ and $\mathbf{d})$ Cell lysates were analyzed by western blotting with an antibody directed against the kinase domain of human Met, against PARP to assess caspase activation, or against GAPDH to assess loading. Arrows indicate full-length Met, p40Met ${ }^{\text {caspase }}$, and the calcium-stress-induced fragment

p40Met ${ }^{\text {calpain }}$ does not exert pro-apoptotic action. To confirm the involvement of calpains, we incubated purified calpain 1 with cell extracts or with the recombinant intracellular domain of Met. In the presence of calcium, cleavage of full-length Met in MCF-10A lysate by purified calpain 1 generated a Met-CTF fragment of the same size as the calcium stress fragment (Figure 4a). Similar proteolytic processing of the recombinant intracellular Met domain was observed in the presence of $2.5 \mathrm{nM}$ calpain, with generation of a major $40-\mathrm{kDa}$ fragment. Further cleavage to smaller fragments was observed with excess protease (Figure $4 \mathrm{~b}$ ).
By analogy to $\mathrm{p} 40 \mathrm{Met}^{\text {caspase }}$, this novel fragment was called p40Met ${ }^{\text {calpain }}$.

Despite many attempts to predict consensual calpain cleavage sites, it seems likely that these proteases recognize secondary and ternary structures, making cleavage sites difficult to identify. ${ }^{34,35}$ To determine the calpain cleavage sequence, we analyzed the in vitro Met cleavage product by mass spectrometry. AspN digestion followed by mass spectrometry revealed that the first $\mathrm{N}$-terminal peptide begins at amino acid D1041, suggesting that cleavage occurs before this sequence (Supplementary Figures S2A and B). 

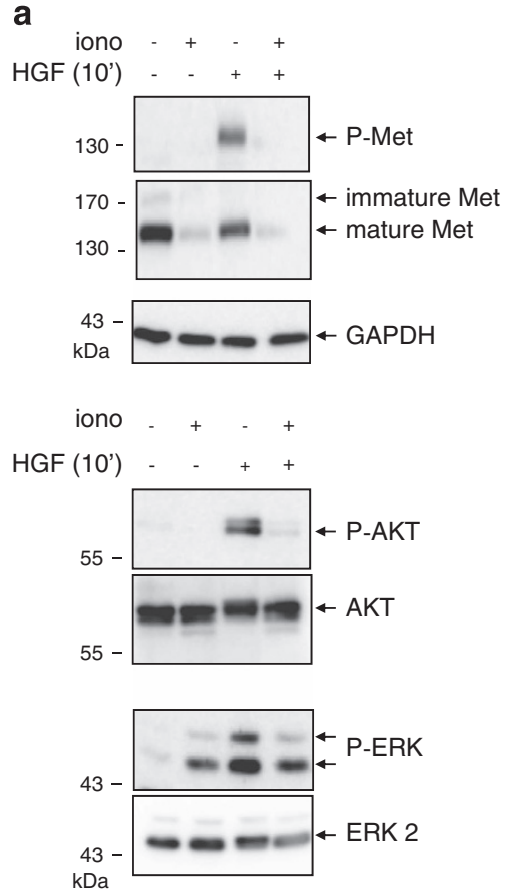

b

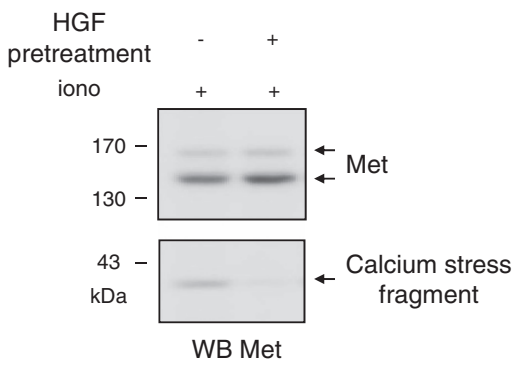

c

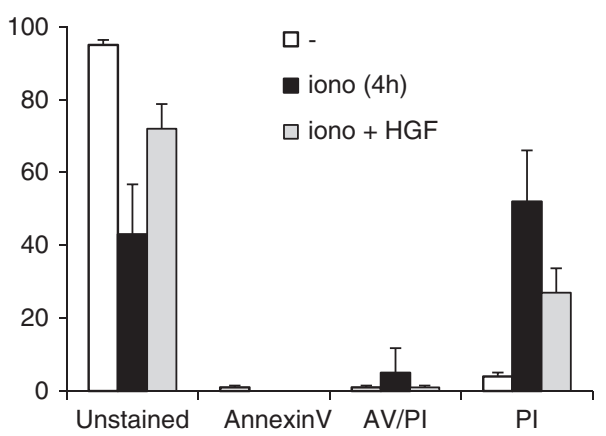

Figure 2 Calcium-stress-induced Met degradation impairs Met survival signaling. (a) MCF-10 A cells were grown for $24 \mathrm{~h}$, serum starved overnight, treated for $1 \mathrm{~h}$ with $1 \mu \mathrm{M}$ ionomycin (iono), and then stimulated or not $10 \mathrm{~min}$ with $10 \mathrm{ng} / \mathrm{ml} \mathrm{HGF/SF}$. (b and c) MCF-10 A cells were grown for $24 \mathrm{~h}$, serum starved overnight in the presence of vehicle or $10 \mathrm{ng} / \mathrm{ml} \mathrm{HGF/SF}$, then treated for $1 \mathrm{~h}$ with $1 \mu \mathrm{M}$ ionomycin and (b) analyzed by western blotting or (c) stained with Annexin V-fluorescein isothiocyanate (FITC) (AV) and PI. (a and b) Cell lysates were analyzed by western blotting with antibodies directed against the kinase domain of human Met, AKT, ERK, or the phosphorylated form thereof (P-Met, P-AKT, or P-ERK) and against GAPDH to assess loading. Arrows indicate the positions of the respective detected proteins

Mass spectrometry also showed that p40Met ${ }^{\text {calpain }}$ still includes the last amino acids of Met. A specific antibody targeting the C-terminal tail of Met detected p40Met ${ }^{\text {calpain }}$ but

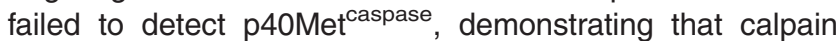
processing of Met preserves its C-terminal end (Supplementary Figure S3). Analysis of the putative calpain cleavage region with the SitePrediction tool ${ }^{34}$ identified a potential cleavage site between residues T1036 and S1037 (Figure 4c). Therefore, we produced in transfected cells expressing an appropriate construct a version of Met starting at residue $\mathrm{S} 1037$ and ending at the natural stop codon. Western blot analysis showed that this fragment has the same molecular weight as endogenous p40Met ${ }^{\text {calpain }}$ (Figure 4d).

We have previously demonstrated that loss of the C-terminal tail of Met is an important step in reshaping Met into a pro-apoptotic factor. 22,23 Because the p40Met ${ }^{\text {calpain }}$ sequence is quite similar to p40Met $^{\text {caspase }}$ but retains the C-terminal tail, we wondered whether p40Met $^{\text {calpain }}$ shares the ability of $\mathrm{p} 40 \mathrm{Met}^{\text {caspase }}$ to induce cell death. When epithelial cells were transfected with a construct encoding either Flagp40Met ${ }^{\text {caspase }}$, Flag-p40Met ${ }^{\text {calpain }}$, or a non-apoptotic version of $\mathrm{p} 40 \mathrm{Met}^{\text {caspase }}$ carrying the $\mathrm{K} 1108 \mathrm{~A}$ mutation, ${ }^{23}$ only Flagp40Met ${ }^{\text {caspase }}$ showed substantial pro-apoptotic activity, leading to $16 \%$ cleaved-caspase-3-positive cells. The respective percentages for $\mathrm{p} 40 \mathrm{Met}^{\text {caspase }}$ and the K1108A mutant were only $\sim 5$ and $2 \%$ (Figures $4 \mathrm{e}$ and $\mathrm{f}$ ).

Calcium stress increases Met shedding, which participates in Met degradation. We next wondered whether the intracellular cleavage yielding p40Met ${ }^{\text {calpain }}$ might also yield a membrane-anchored Met-NTF. Immunostaining with two distinct antibodies failed to reveal any Met-NTF at the membrane surface of MCF-10A cells undergoing necrosis (Figure 5a). Western blotting also failed to reveal the MetNTF (Figures $5 \mathrm{~b}$ and $\mathrm{c}$ ). In contrast, analysis of conditioned medium revealed abundant accumulation of an $\mathrm{N}$-terminal fragment of $\sim 95 \mathrm{kDa}$ (Figures $5 \mathrm{~b}$ and $\mathrm{c}$ ). These results suggest that, in addition to calpain processing, Met undergoes an extracellular cleavage releasing its $\mathrm{N}$-terminal region into the medium. According to its apparent size, this $\mathrm{N}$-terminal fragment could be Met-NTF, generated by Met shedding mediated by ADAM metalloproteases during PS-RIP. ${ }^{18}$

The ionomycin-induced appearance of Met-NTF in the conditioned medium was efficiently inhibited by the metalloprotease inhibitor TAPI (TNF- $a$ processing inhibitor), but not by the calpain inhibitor calpeptin (Figure 5d). TAPI treatment did not affect $p 40 \mathrm{Met}^{\text {calpain }}$ generation, indicating that the two proteolytic processes are independent. Furthermore, in contrast to calpeptin treatment, TAPI treatment was found to rescue full-length Met, indicating that shedding is the major event involved in Met degradation during calcium stress (Figure 5d).

Shedding of the Met-NTF generates a C-terminal counterpart of $\sim 55 \mathrm{kDa}$ (Met-CTF), which is efficiently degraded by the lysosome or further cleaved by $\gamma$-secretases. ${ }^{18,19}$ Consistently with this, ionomycin treatment led to increased detection of Met-CTF when this fragment was stabilized by 
a
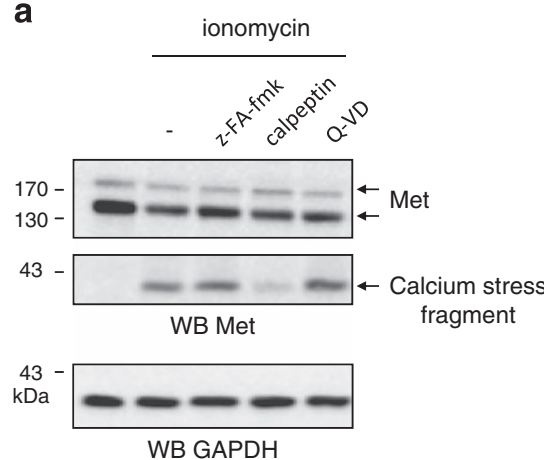

C
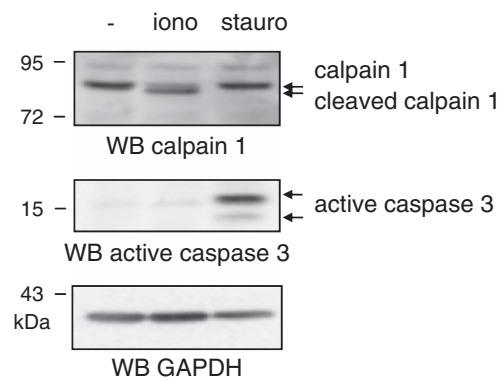

b

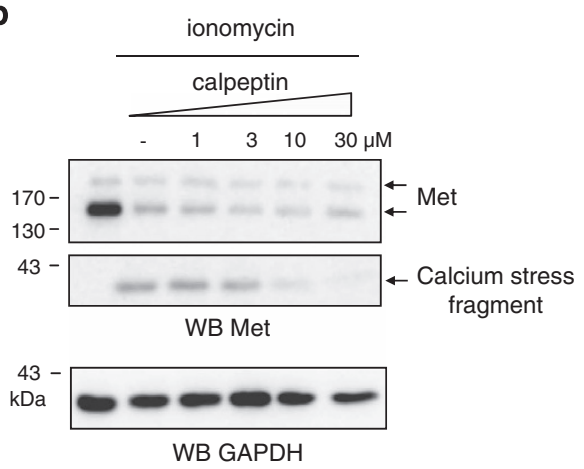

d
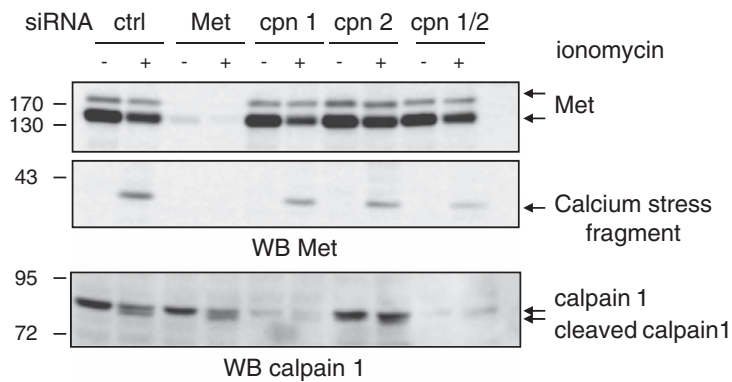

WB calpain 1
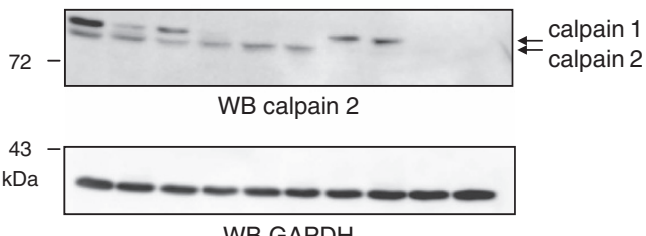

Figure 3 lonomycin induces intracellular Met cleavage by calpains. MCF-10A cells were grown for $24 \mathrm{~h}$, serum starved and treated with (a) $20 \mu \mathrm{M}$ cathepsin inhibitor Z-FAFMK, calpain inhibitor calpeptin, or pan-caspase inhibitor QVD or (b) increasing concentrations of calpeptin. They were then treated for $1 \mathrm{~h}$ with $1 \mu \mathrm{M}$ ionomycin (iono). (c) MCF-10A cells were grown for $24 \mathrm{~h}$, serum starved, and treated for $1 \mathrm{~h}$ with $1 \mu \mathrm{M}$ ionomycin or for $6 \mathrm{~h}$ with $1 \mu \mathrm{M}$ staurosporine (stauro). (d) MCF-10A cells were transfected with the same amount of siRNA. The siRNAs tested were as follows: control siRNAs, siRNAs targeting Met or calpain 1 or calpain 2, or a mix of siRNAs targeting calpain 1 and calpain 2. On the next day, they were serum starved overnight and treated for $1 \mathrm{~h}$ with $1 \mu \mathrm{M}$ ionomycin. (a-d) Cell lysates were analyzed by western blotting with an antibody directed against either the kinase domain of human Met, calpain 1, calpain 2, cleaved caspase 3, or GAPDH to assess loading. Arrows indicate the respective positions of the detected proteins and their cleaved forms. Sequential reprobing with calpain 1 and calpain 2 resulted in detection of both proteases (d)

treatment with lysosome and $y$-secretase inhibitors. This confirms that Met undergoes metalloprotease-mediated shedding during necrosis (Supplementary Figure S4). To assess whether Met-CTF is generated upon receptor cleavage within the extracellular juxtamembrane region, we looked for MetCTF in MDCK cells expressing either an uncleavable chimeric receptor (uncleavable tropomyosine receptor kinase (TRK)Met, in which the entire extracellular domain of Met is replaced with the extracellular domain of the TRKA receptor) or a cleavable chimera in which the first 50 juxtamembrane extracellular amino acids of Met are present (cleavable TRKMet; Supplementary Figure S5A). ${ }^{18,19}$ As expected, cotreatment with $\gamma$-secretase and lysosome inhibitors stabilized Met-CTF and the full-length chimera only in cells expressing the cleavable TRK-Met. In these cells, calcium ionophore treatment was found to increase Met-CTF generation, with a concomitant decrease in full-length chimera (Supplementary Figure S5B). In contrast, cells expressing the uncleavable chimera showed no generation of Met-CTF and no degradation of the full-length chimera. Taken together, these data demonstrate that during calcium-stress-induced necrosis, Met is processed by both calpain and metalloproteases, participating in its efficient degradation over a few minutes.

Met proteolytic processing in lung tumors. In previous studies and the present one, we have shown that the Met receptor can be cleaved during various physiological processes (Figure 6a). ${ }^{18,21}$ Although many immunohistochemistry (IHC) studies have shown Met to be overexpressed in a variety of cancers, ${ }^{14}$ the Met cleavage state was never characterized in these studies. About half of all non-small-cell lung cancers (NSCLCs) are known to overexpress Met. We thus analyzed the amount and state of Met by both IHC and western blotting in a library of 13 surgically resected NSCLCs (Supplementary Figure S6A).

Among the tumor samples, four displayed a score of 0 , two a score of 1 , five a score of 2 , and two a score of 3 (Supplementary Figure S6B). Representative Met IHC images are shown (Figure 6b). The amount of full-length Met detected on western blots of tumor lysates was found to correlate, 
a

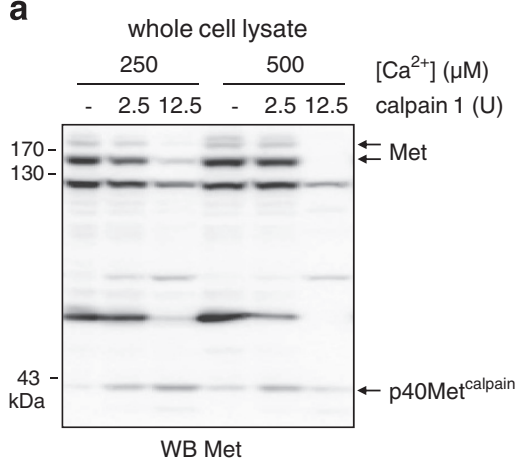

C

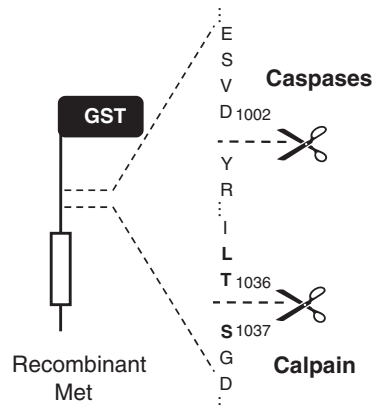

e

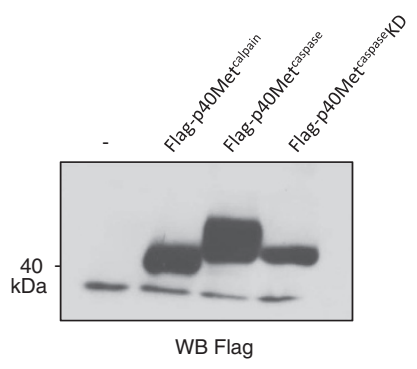

b

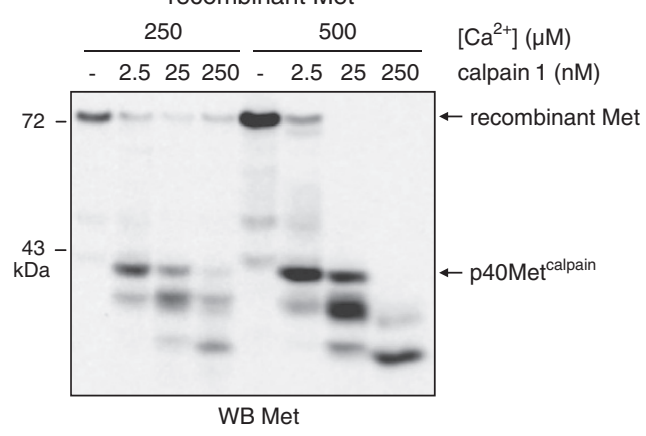

d

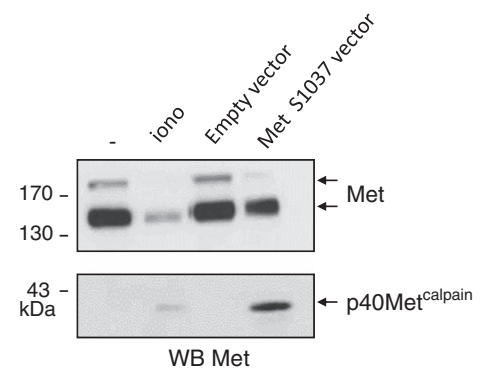

f

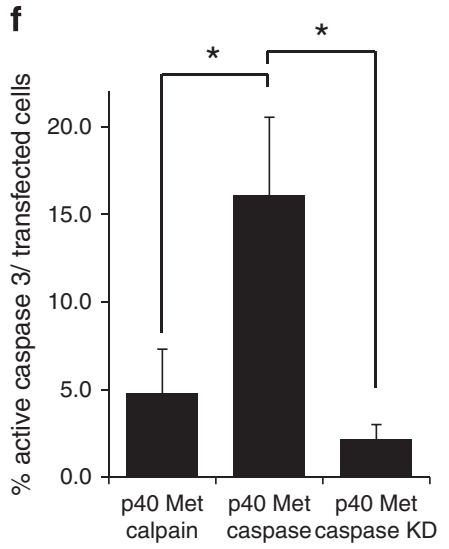

Figure 4 Reconstitution of p40Met ${ }^{\text {calpain }}$ and evaluation of its apoptotic properties. (a) Equal amounts of extract obtained by lysing MCF-10A cells in LR buffer or (b) 5 ng purified recombinant intracellular Met domain were incubated with the indicated concentration of $\mathrm{CaCl}_{2}$ and purified calpain 1 for 30 min. (c) Schematic representation of the caspase and calpain cleavage sites in the juxtamembrane domain of Met. (d) MCF-10 A cells were grown for $24 \mathrm{~h}$ and either serum starved and treated for $1 \mathrm{~h}$ with $1 \mu \mathrm{M}$ ionomycin (iono) or transfected with a vector expressing the Met S1037 variant. (a, b and $\mathbf{d}$ ) Cell lysates were analyzed by western blotting with an antibody directed against the kinase domain of human Met. Arrows indicate the positions of Met, recombinant Met, and p40Met ${ }^{\text {calpain }}$. (e) HEK cells were transfected with empty vector or a vector expressing Flag-tagged versions of p40Met ${ }^{\text {caspase }}$, p40Met ${ }^{\text {caspase }} \mathrm{K} 1108 \mathrm{~A}$ (kinase dead, KD), or p40Met ${ }^{\text {calpain }}$. Twenty-four hours later, the cells were lysed and lysates were analyzed by western blotting with an antibody directed against Flag. (f) MCF-10A cells were cultured on glass coverslips and transfected with the indicated Flag-p40Met. Twenty-four hours later, the cells were fixed and stained with antibodies against Flag and active caspase 3. Flag-positive cells (expressing p40 Met) and displaying active caspase 3 staining were counted. About 1000 flag-positive cells were counted per well and percentage was calculated $\left(n=3 ; \pm\right.$ S.D.). The $P$-value of Student's $t$-test is shown ( $\left.{ }^{\star} P<0.05\right)$

globally, with the Met IHC score (Figure 6c and Supplementary Figure S7). In addition, several Met fragments were detected in tumors with two different antibodies directed against the intracellular region, and their levels were found to correlate with that of full-length receptor (Supplementary Figure S7). Immunoblotting with an antibody directed against the extracellular domain confirmed the full-length Met score and allowed detection of abundant Met-NTFs of $\sim 95 \mathrm{kDa}$, the likely $\mathrm{N}$-terminal counterparts of the $\mathrm{C}$-terminal fragments.
The main C-terminal fragments observed in tumors, $\sim 55$, 45 , and $40 \mathrm{kDa}$ in size, are similar in size to the fragments identified in previous studies and the present one. To assess this, we carried out co-migration of three high-Met tumor lysates with cell extracts containing generated or stabilized Met fragments. Met-CTF was stabilized by treatment with $\gamma$-secretase and lysosome inhibitors, p45 Met was generated in highly confluent cells (manuscript under revision), and p40Met ${ }^{\text {caspase }}$ and p40Met ${ }^{\text {calpain }}$ were generated by inducing 
a

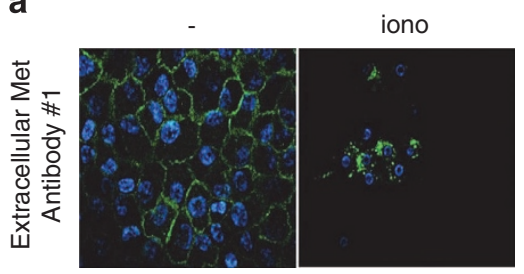

b

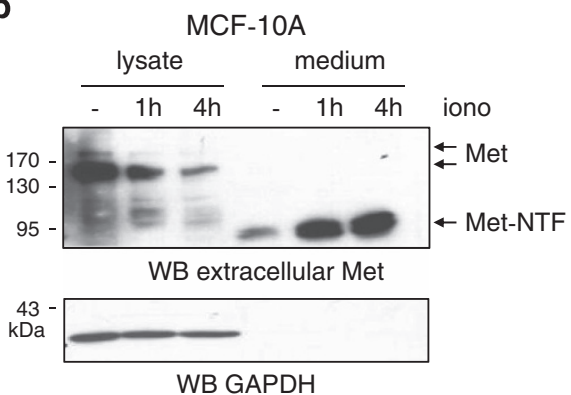

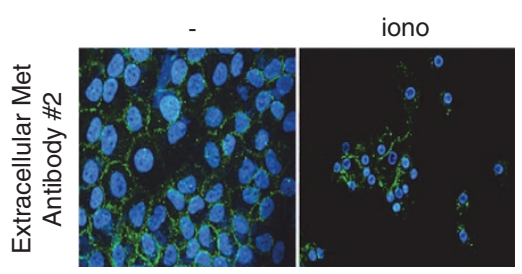

C

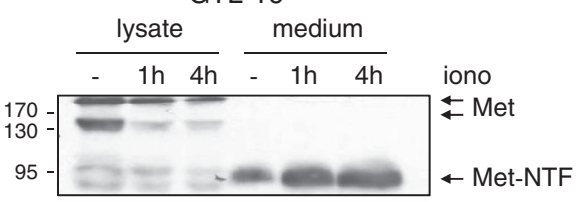

WB exatracellular Met

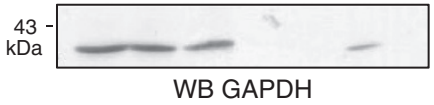

d

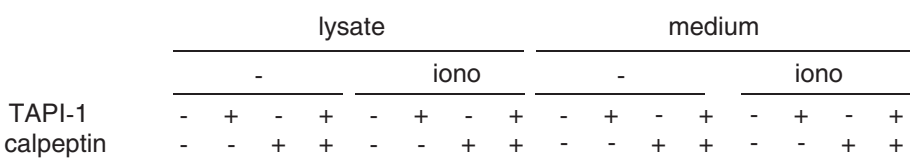
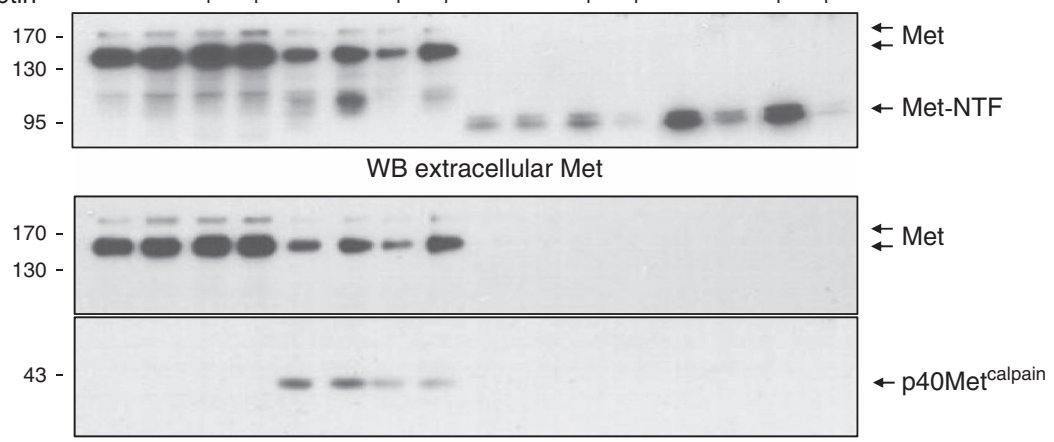

WB intracellular Met

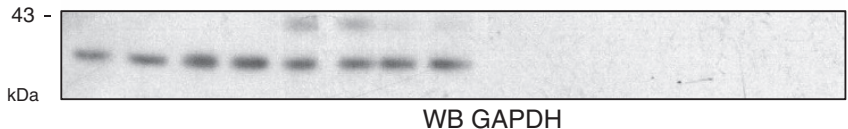

Figure 5 Ionomycin (iono) treatment increases Met shedding. (a) MCF-10A cells were grown on glass coverslips, serum starved overnight, and treated with vehicle or $1 \mu \mathrm{M}$ ionomycin for $4 \mathrm{~h}$. Immunofluorescence staining was performed with two different antibodies directed against the Met extracellular region and the nuclei were stained with Hoechst. (b) MCF-10 A and (c) GTL-16 cells were grown for $24 \mathrm{~h}$, serum starved overnight, and treated with $1 \mu \mathrm{M}$ ionomycin for the indicated time. Both cell lysates and an equal volume of conditioned medium were analyzed by western blotting with an antibody against the Met extracellular region. (d) MCF-10A and GTL-16 cells were grown for $24 \mathrm{~h}$, serum starved, and pretreated overnight with TAPI-1 and/or calpeptin, and treated for $1 \mathrm{~h}$ with $1 \mu \mathrm{M}$ ionomycin. Cell lysates and conditioned medium were analyzed by western blotting with an antibody against the Met extracellular region, the Met kinase domain (intracellular Met), and GAPDH to assess loading. Arrows indicate positions of full-length Met, MetNTF, and p40Met ${ }^{\text {calpain }}$

apoptosis or necrosis, respectively, (Figure 6c). The apparent molecular weights of these four fragments perfectly matched those of the Met fragments observed in tumors. It is worth noting that 11 of the 13 tumors had not been subjected to any treatment, suggesting that the Met fragments were not the result of stress induced by therapeutic agents. Unlike the antibodies targeting the Met receptor, an antibody directed against the intracellular domain of epidermal growth factor receptor failed to detect any intracellular fragments. Altogether, these results suggest that proteolytic degradation of the Met receptor is drastically increased in lung cancers overexpressing Met.

\section{Discussion}

Necrosis is a caspase- and ATP-independent cell death process characterized by a loss of plasma membrane and organelle integrity. It lacks features of apoptosis, such as phosphatidylserine externalization and apoptotic body release. Although first defined as accidental cell death, necrosis is currently regarded as a programmed cell death mechanism, as pharmacological inhibitors or gene deletions can protect cells from this demise. Some necrotic cell death can be induced by calcium overload, for example, in neural cells in the case of neurodegenerative disorders or following 
a
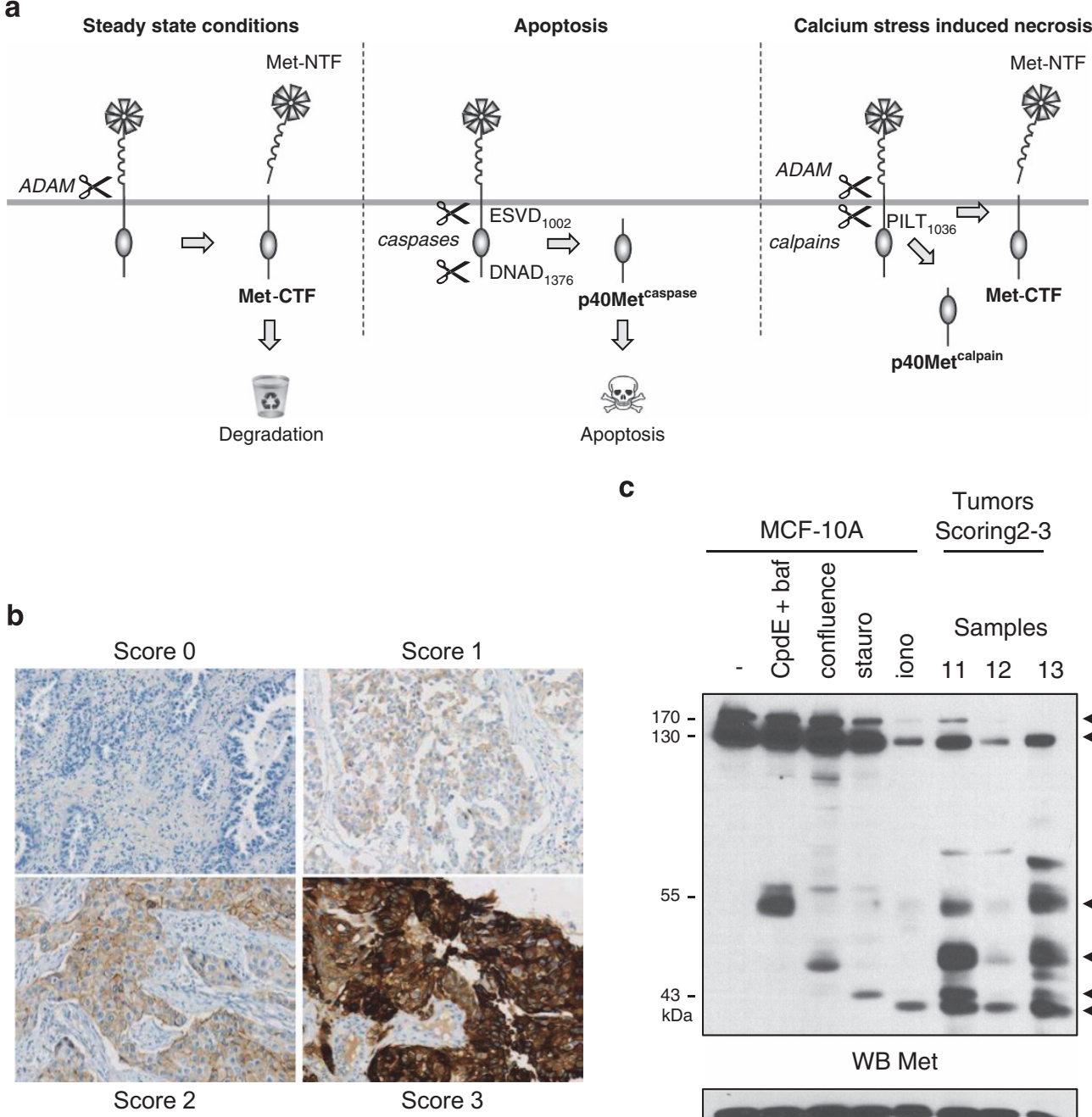

C

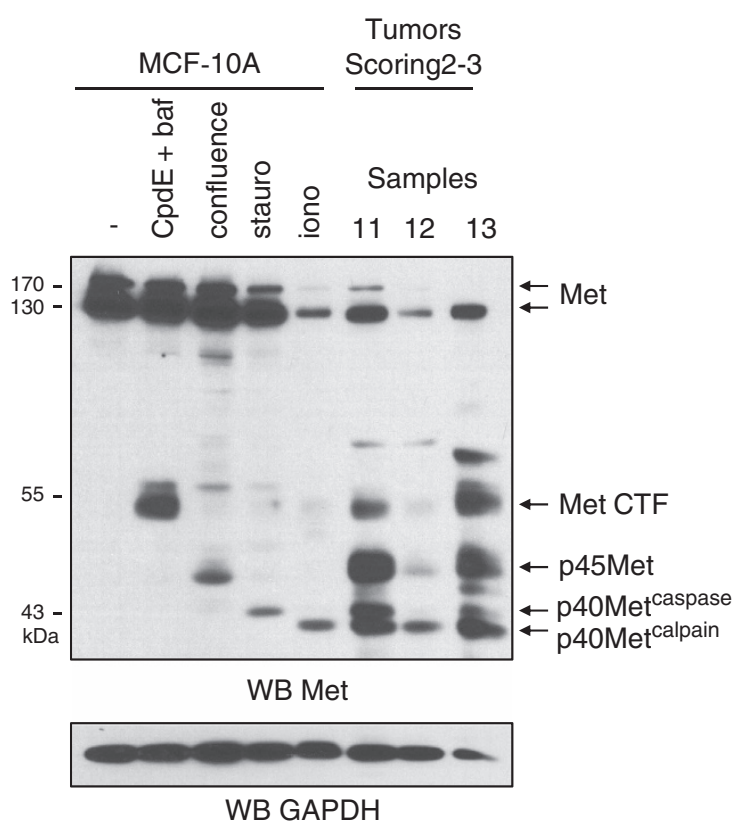

Figure 6 Met fragments are produced in NSCLC tumors overexpressing Met receptor. (a) Schematic representation of the different cleavages of the Met receptor. Under steady-state conditions, membrane metalloproteases cause shedding of an N-terminal fragment (Met-NTF) into the extracellular space, with formation of an unstable membraneanchored C-terminal fragment (Met-CTF). During apoptosis, cleavage of Met by caspases generates p40Met ${ }^{\text {caspase }}$, a pro-apoptotic fragment of $\sim 40 \mathrm{kDa}$. During calcium-stressinduced necrosis, Met is cleaved by both metalloproteases (to Met-NTF and Met-CTF) and calpains (to p40Met ${ }^{\text {calpain }}$ ). (b) Tumor samples were analyzed by IHC to determine the level of Met. (c) Three tumor samples overexpressing Met were analyzed by western blotting, by comparison with MCF-10A cell lysates treated for $5 \mathrm{~h}$ with $1 \mu \mathrm{M}$ compound E and $5 \mathrm{nM}$ bafilomycin (CpdE+baf), for $6 \mathrm{~h}$ with $1 \mu \mathrm{M}$ staurosporine (stauro), for $1 \mathrm{~h}$ with $1 \mu \mathrm{M}$ ionomycin (iono), or cultured to high density (confluence)

ischemia. ${ }^{36}$ In the case of cancer cells, cells deficient in Bak (Bcl-2 antagonist/killer) and Bax (Bcl-2-associated X-protein), which are resistant to many apoptosis inducers, have been found to die from necrosis following calcic stress. ${ }^{33}$ Yet the mechanisms underlying calcium-stress-induced necrosis are still poorly understood. As Met is actively involved in both survival and apoptosis, we have sought to determine its fate and potential role during calcium-stress-induced necrosis.

We demonstrate here that calcium-stress-induced necrosis causes a substantial decrease in Met within minutes following treatment with a calcium ionophore. Consistently with this decrease, HGF stimulation can no longer induce Met phosphorylation or activation of downstream signaling pathways under these conditions. This Met degradation might prevent cell protection triggered by ligand-dependent activation of Met. Rapid Met degradation, associated with detection of fragments, suggests that Met undergoes proteolytic cleavages during this process. Accordingly, we have found that Met is cleaved by both calpains and membrane metalloproteases. We show that p40Met ${ }^{\text {calpain }}$ generation can be inhibited efficiently by treatment with a pharmacological calpain inhibitor and partially by means of interfering RNAs targeting calpains 1 and 2 . This demonstrates that these two proteases, and likely other calpains, are involved in Met cleavage. We demonstrate as well that calcium stress induces autocatalytic cleavage of calpain 1, consistent with activation of calpain by the intracellular calcium level. ${ }^{37,38}$ In vitro cleavage of Met by calpain 1 generates a main fragment of $\sim 40 \mathrm{kDa}$, confirming the involvement of calpain 1 .

Our mass spectrometry and immunoblot analyses reveal juxtamembrane cleavage, possibly at the $\mathrm{LT}_{1036}-\mathrm{S}_{1037}$ sequence, and the presence of the Met C-terminal tail in 
p40Met ${ }^{\text {calpain. }}$. Thus, the p40Met ${ }^{\text {caspase }}$ and $\mathrm{p} 40 \mathrm{Met}^{\text {calpain }}$ fragments differ at both their $\mathrm{N}$ - and C-terminal ends. Consistently with the fact that p40Met $^{\text {calpain }}$ retains the C-terminal tail of Met, known to prevent its pro-apoptotic action, ${ }^{22}$ we show here that it does not induce increased caspase 3 activity and is thus not a pro-apoptotic fragment.

In addition to intracellular p40Met $^{\text {calpain }}$, calcium overload induces an increase in two other Met fragments: Met-NTF (in conditioned medium) and the labile Met-CTF, both known to be generated by PS-RIP. ${ }^{18}$ A metalloprotease inhibitor was found to impair production of these fragments and to rescue the full-length Met receptor, demonstrating that calcium stress triggers Met shedding. It is worth noting that inhibition of calpain activity did not rescue full-length Met, suggesting that PS-RIP is the main contributor to the latter's disappearance. The contribution of calpain is hard to assess, as calpain inhibitors only reduced, but did not totally prevent, p40Met ${ }^{\text {calpain }}$ generation.

Although Met PS-RIP is mainly involved in Met degradation through generation of labile intracellular fragments, the released Met-NTF is stable and can act as a decoy for HGF/SF. ${ }^{19,39-41}$ During calcium-stress-induced necrosis, the amount of released Met-NTF strongly increased, suggesting an increased decoy effect. We thus propose that during calcium-stress-induced necrosis, cleavages decrease the amount of Met receptor and generate a potential extracellular decoy fragment. Interestingly, the $\mathrm{N}$-terminal counterpart of p40Met ${ }^{\text {caspase }}$ is a membrane-anchored fragment that can act as a decoy for HGF/SF. ${ }^{42}$ Hence, the stable N-terminal Met fragment generated during apoptosis could be a membraneanchored decoy, while the fragment generated during calcium stress could be a released decoy, both decoys being able to cause inhibition of an HGF/SF-induced survival response. In the future, it will thus be important to evaluate the decoy role of Met-NTF and its importance in necrosis expansion to the surrounding tissues.

HGF/SF stimulation partially protects cells against calciumionophore-induced necrosis and reduces Met cleavage by calpain. Other growth factors have also been shown to protect cells against necrosis, such as the insulin-like growth factor-1, which inhibits calcium-ionophore-induced photoreceptor cell death through expression of the calpain inhibitor calpastatin. ${ }^{43}$ Although the anti-apoptotic properties of HGF/SF have been well described, ${ }^{44}$ further work is needed to elucidate the necrosis-countering pro-survival mechanisms of this ligand.

In NSCLC tumors overexpressing Met, we have identified several C-terminal fragments, including the previously identified Met-CTF (p55 Met), p45 Met generated in highly confluent cells (manuscript under revision), p40Met ${ }^{\text {caspase }}$, and p40Met ${ }^{\text {calpain }}$. These fragments were mainly detected in tumors showing high levels of full-length Met, except for p40Met ${ }^{\text {calpain }}$, detectable in low-scoring tumors. Thus, full-length Met is responsible for only part of the detected signal, as its presence is accompanied by that of multiple $\mathrm{C}$-terminal fragments. This suggests that the level of full-length Met could be overestimated in tumor cells evaluated by IHC. In addition, although the subcellular localization of Met is difficult to establish by IHC, these tumor cells display both plasma membrane and cytoplasmic staining. The latter might be associated with detection of Met C-terminal fragments such as the p40Met ${ }^{\text {caspase }}$ and
p40Met ${ }^{\text {calpain }}$. Consistently, a cytoplasmic and even a nuclear localization of Met have been described in breast cancer samples and mesothelioma tumors. ${ }^{45,46}$

We demonstrated in cell lines that p40 $\mathrm{Met}^{\text {caspase }}$ and p40 Met $^{\text {calpain }}$ are generated by different molecular mechanisms, and that they do not coexist in the same cell. Because Met fragments produced in NSCLC samples were detected by western blot, which involve the lysis of a cell population, we cannot assert that p40 Met ${ }^{\text {caspase }}$ and p40 Met ${ }^{\text {calpain }}$ are not produced in the same cells of the tumor. However, it is well established that tumor tissues undergo various stresses influencing differently the cell fates. Thus, the diversity of detected Met fragments might correspond to a diversity of cellular conditions within lung tumors. For instance, the presence of $\mathrm{p} 40 \mathrm{Met}^{\text {caspase }}$ might be associated with apoptotic cells, whereas the presence of $\mathrm{p} 40 \mathrm{Met}^{\text {calpain }}$ might be associated with a necrotic area. In these tumor samples, necrotic areas are indeed frequently observed and correlate with a strong decrease of total Met (data not shown). Detection of the labile Met-CTF (p55 Met) in tumor samples suggests that lysosomal degradation is altered in these tumors or that the amount of generated fragment exceeds the capacity of the cells to degrade it. We have demonstrated in a cell model that most of the Met fragments are associated with degradation of the full-length Met receptor. Thus, in tumor samples overexpressing Met, several proteolytic degradation mechanisms might compensate for receptor overexpression, thus limiting the amount of receptor.

At first glance, the mechanism of Met degradation appears similar during apoptosis and calcium-stress-induced necrosis: in both cases, it involves generation of an intracellular fragment of $\sim 40 \mathrm{kDa}$. In both processes, the extra cellular ligand-binding domain of Met is separated from the intracellular kinase domain, preventing survival. Calciumstress-induced necrosis, however, triggers a more complex proteolytic process, also involving cleavage by membrane metalloproteases. Consequently, the cleavages occurring during necrosis are quicker than caspase cleavages, leading to Met degradation within minutes of stress induction. In addition, while p40Met ${ }^{\text {caspase }}$ somewhat resembles p40Met ${ }^{\text {calpain }}$, these two fragments appear to be functionally different: the former can favor cell death while the latter is unable to promote such a response.

\section{Materials and Methods}

Cytokines, drugs, and cell cultures. lonomycin and A23187 were purchased from Santa Cruz Biotechnology (Dallas, TX, USA). Staurosporine was obtained from Sigma-Aldrich (St Louis, MO, USA). Purified calpain 1 was obtained from Calbiochem (San Diego, CA, USA). Recombinant human HGF was obtained from Peprotech (Rocky Hill, CT, USA). The caspase inhibitor QVD-OPh (N-(2quinolyl)-L-valyl-L-aspartyl-(2,6-difluorophenoxy) methylketone), the calpain inhibitors ALLN (N-Acetyl-L-leucyl--Lleucyl--L-norleucinal) and calpeptin, the metalloprotease inhibitor TAPI-1, and the H+-pump inhibitor bafilomycin A1 were purchased from Calbiochem. The cathepsin inhibitor Z-FA-FMK (Z-Phe-Ala fluoromethyl keton) was obtained from Bachem (Budendaurf, Switzerland). The proteasome inhibitor lactacystin was from Sigma-Aldrich. The $\gamma$-secretase inhibitor compound $\mathrm{E}$ was from Alexis/Coger (Lausen, Switzerland).

MDA-MB-231 and GTL-16 cells were cultured in Dulbecco's Modified Eagle's Medium (Life Technologies, Carlsbad, CA, USA) supplemented with 10\% fetal bovine serum (FBS; Life Technologies) and 1\% antibiotics (penicillin (10 $000 \mathrm{U} / \mathrm{ml})$-streptomycin $(10000 \mu \mathrm{g} /$ $\mathrm{ml})$; Life Technologies). HEK-293T cells were cultured in DMEM supplemented with $10 \%$ FBS, $1 \%$ non-essential amino acids (Life Technologies), and antibiotics. MCF-10 A cells were cultured in DMEM and HAM's F12 (vol/vol, Life Technologies) supplemented with 
$5 \%$ horse serum (Life Technologies), $500 \mathrm{ng} / \mathrm{ml}$ hydrocortisone (Calbiochem), $20 \mathrm{ng} / \mathrm{ml}$ epidermal growth factor (Peprotech), $10 \mu \mathrm{g} / \mathrm{ml}$ insulin (Sigma-Aldrich), $100 \mathrm{ng} / \mathrm{ml}$ cholera toxin (Calbiochem), and 1\% antibiotics. Calcium-free DMEM was purchased from Life Technologies.

Antibodies. Rabbit polyclonal antibodies directed against phosphorylated (Y1234/1235) Met (no. 3126), phosphorylated (S473) Akt (no. 9271), and active caspase 3 (no. 9661) and mouse monoclonal antibody directed against phosphorylated (T202/Y204) Erk were purchased from Cell Signaling Technology (Danvers, MA, USA). Mouse monoclonal antibody against the kinase domain of Met (3D4) was purchased from Life Technologies. Mouse monoclonal antibody against glyceralehyde-3-phosphate dehydrogenase (GAPDH; 6C5-32233), rabbit polyclonal antibodies against the C-terminal domain of human PARP-1 (H250), against Akt (H136), and against ERK2 (C14), and goat polyclonal antibodies against the calpain 1 large subunit (C-20) and the calpain 2 large subunit (C-19) were purchased from Santa Cruz Biotechnology. Rabbit monoclonal antibody directed against the C-terminal tail of Met (SP44) was purchased from Roche (Schlieren, Switzerland). Mouse monoclonal antibody directed against the extracellular domain of Met (MAB3582) and goat polyclonal antibody directed against the extracellular domain of Met (AF276) were purchased from R\&D Systems (Minneapolis, MN, USA). Mouse monoclonal antibody directed against the C-terminal domain of Met (DL-21) was kindly provided by Dr. Sylvia Giordano (University of Torino Medical School, Italy). Regions recognized by the anti-Met antibodies are shown in the Supplementary Figure S8. Mouse monoclonal antibody directed against Grb2 (growth factor receptor-bound protein 2; 81/GRB2) was purchased from BD Transduction Laboratories (San Jose, CA, USA). Green-fluorescent Alexa Fluor 488-conjugated anti-mouse $\operatorname{lgG}(\mathrm{H}+\mathrm{L})$ and red-fluorescent Alexa Fluor 594-conjugated anti-rabbit IgG $(\mathrm{H}+\mathrm{L})$ were purchased from Life Technologies. Rabbit polyclonal antibodies against the Flag epitope were purchased from SigmaAldrich. Rabbit polyclonal antibody directed against tubulin (PM054) was purchased from Medical and Biological Laboratories (Nagoya, Japan).

Plasmid constructs. The vector expressing Flag-p40Met ${ }^{\text {caspase }}$ was constructed as described previously. ${ }^{22}$ The vector expressing p40Met ${ }^{\text {calpain }}$ (Met S1037-S1390) was constructed as follows. The portion of Met between D1030 and S1390 was amplified by PCR from pRS2 hu Met (kindly provided by Dr. G Vande Woude, Van Andel Research Institute, MI, USA) used as template, with the following primers $5^{\prime}$-AGGGATCCATGGACATGTCCCCCATCCTAACTAG-3' containing a BamH1 restriction site and 5'-AGCTCGAGCTATGATGTCTCCCAGAAGGAG-3' containing a Xho1 restriction site. The PCR product was subcloned into pcDNA3 between the BamH1 and Xho1 restriction sites. The amino acids D1030-S1037 were removed with the QuikChange site-directed mutagenesis system of Stratagene (Santa Clara, CA, USA), with the following primers: 5'-GTACCGAGCTC GGATCCATGAGTGGGGACTCTGATATATC-3' and 5'- GATATATCAGAGTCCCCA CTCATGGATCCGAGCTCGGTAC-3'. The vector expressing Flag-p40Met ${ }^{\text {calpain }}$ was constructed as follows. pcDNA3 p40Met ${ }^{\text {calpain }}$ was subcloned into pcDNA3 FLAG between the BamH1 and Xho1 restriction sites.

Transfections and RNA interference. Transfections of HEK-293T and MCF-10 A cells with the reagents polyethyleneamine Exgen 500 (Euromedex, France), and Jet Prime (Polyplus Transfection, Illkirch, FRANCE) were performed as previously described. ${ }^{22,23}$ For gene silencing, a suspension of 400000 cells was incubated for $20 \mathrm{~min}$ with a mix of $3 \mu \mathrm{l} / \mathrm{ml}$ Lipofectamine 2000 (Invitrogen) and $60 \mathrm{nM}$ small interfering RNA (siRNA), and then plated in a six-well plate in complete medium. The Met-targeting siRNAs were a pool of three stealth siRNAs (Invitrogen) (5'-CCAUUUCAACUGAGUUUGCUGUUAA-3', 5'-UCCAGAAGAUCAGUUUCCUA AUUCA-3', and 5'CCGAGGGAAUCAUCAUGAAAGAUUU- ${ }^{\prime}$ ). The corresponding pool $(3 \mathrm{mM})$ was mixed with control siRNA so as to achieve a total siRNA concentration of $60 \mathrm{nM}$. The siRNAs targeting calpain 1 and calpain 2 (SigmaAldrich) were pools of two siRNAs: calpain 1: (5'-CUAUUGGCUUCGCGGUCUA dTdT-3' and 5'-GGAACAACGUGGACCCAUAdTdT-3') and calpain 2: (5'-CGCUA UUCAAGAUAUUUAAdTdT- $3^{\prime}$ and $5^{\prime}$-GAAACUGAUCCGCAUCCGAdTdT-3'). Mixtures totaling $60 \mathrm{nM}$ siRNA, containing each pool at $30 \mathrm{nM}$ or one pool at $30 \mathrm{nM}$ and a control siRNA at $30 \mathrm{nM}$, were prepared.

Western blotting. Western blotting was performed as previously described. ${ }^{47}$

Immunofluorescence staining. Cells were grown on glass coverslips for $24 \mathrm{~h}$ and then washed, fixed in $4 \%$ paraformaldehyde at room temperature for $10 \mathrm{~min}$, and permeabilized in PBS $1 \times$ and $0.5 \%$ Triton X-100 at room temperature for $10 \mathrm{~min}$.
The cells were then washed and blocked in PBS and $0.2 \%$ casein for 30 min. Primary antibodies were incubated for $1 \mathrm{~h}$ at room temperature, either alone (mouse antiextracellular Met antibody $(10 \mu \mathrm{g} / \mathrm{ml})$ or goat anti-extracellular Met antibody $(4 \mu \mathrm{g} / \mathrm{ml})$ ) or in combination (anti-Flag antibody $(1 \mu \mathrm{g} / \mathrm{ml})$ and anti-active caspase 3 antibody $(1: 500))$. The cells were washed with PBS and incubated for $60 \mathrm{~min}$ at room temperature with secondary antibodies diluted to $2 \mu \mathrm{g} / \mathrm{ml}$. Secondary antibodies were used alone (green-fluorescent Alexa Fluor 488-conjugated anti-goat lgG $(\mathrm{H}+\mathrm{L})$, far redfluorescent Alexa Fluor 647-conjugated anti-rabbit lgG $(\mathrm{H}+\mathrm{L})$ ) or in combination (greenfluorescent Alexa Fluor 488-conjugated anti-mouse $\lg G(\mathrm{H}+\mathrm{L})$ and red-fluorescent Alexa Fluor 594-conjugated anti-rabbit lgG $(H+L))$. The cells were washed with PBS and the nuclei were counterstained with Hoechst 33258 . Coverslips were mounted with glycergel mounting medium (Dako, Carpenteria, CA, USA). Slides were observed in oil immersion with an Axiolmager Z1 (Carl Zeiss), numerical aperture, ECL-PLAN NEOFLUAR $\times 40$ NA 1.3, with a monochrome Zeiss AxioCam MRm camera and Zen Blue acquisition software.

Cell death determination. Cells were trypsinized and analyzed with the Tali Apoptosis Kit (Life Technologies). Briefly, cells were harvested by centrifugation and incubated with Alexa Fluor 488-conjugated Annexin V and PI. Then staining was measured with a Tali image-based cytometer (Life Technologies) to determine the amounts of unstained, singly stained, and doubly stained cells.

In vitro calpain cleavage and mass spectrometry. Cells were lysed in lysis and reaction (LR) buffer (100 mM HEPES, $\mathrm{pH}=7.4,150 \mathrm{mM} \mathrm{NaCl}$, and $1 \%$ Triton X-100). Equal amounts of cell lysate or $5 \mathrm{ng}$ recombinant human Met were incubated at $30^{\circ} \mathrm{C}$ with the indicated concentrations of purified calpain 1 and $\mathrm{CaCl}_{2}$. The reaction was stopped by adding $3 \times$ Laemmli buffer and heating at $95^{\circ} \mathrm{C}$ for $4 \mathrm{~min}$. Samples were analyzed by western blotting.

For mass spectrometry, $900 \mathrm{ng}$ recombinant human Met was incubated at $30^{\circ} \mathrm{C}$ for $30 \mathrm{~min}$ in LR buffer with $250 \mu \mathrm{M} \mathrm{CaCl}_{2}$ and $2.5 \mathrm{nM}$ purified calpain 1 . The reaction was stopped by adding $3 \times$ Laemmli buffer and heating the sample at $95^{\circ} \mathrm{C}$ for $4 \mathrm{~min}$. After electrophoresis, the polyacrylamide gel was fixed in $40 \%$ methanol, $7 \%$ acetic acid solution and stained with Coomassie blue. Stained band corresponding to Met fragment was excised from the gel, reduced, alkylated with iodoacetamide $(10 \mathrm{mg} / \mathrm{ml}$ in $20 \mathrm{mM} \mathrm{NH}_{4} \mathrm{HCO}_{3}$ ), and digested overnight with $100 \mathrm{ng} \mathrm{AspN}$ endoproteinase (Pierce, Rockford, IL, USA). The resulting peptide mixture was eluted from the gel, desalted, and spotted onto a MALDI plate with freshly dissolved $\alpha$-cyano-4hydroxycinnaminic acid (10 mg/ml in 50\% $\mathrm{CH}_{3} \mathrm{CN}$, TFA $\left.1 / 1000\right)$. Mass spectrometry was performed by MALDI-TOF-TOF Autoflex Speed (Bruker Daltonics, Fremon, CA, USA). MS and MS/MS data were analyzed with BioTools software (Fremon, CA, USA). Peptides were identified with Mascot, http://www.matrixscience.com/.

Tumor sample preparation. After surgery, tumor samples were divided into two parts. One was frozen in a Snapfrost fast freezing system (Excilone, Aperio, CA, USA) and stored at $-80^{\circ} \mathrm{C}$, and the other was formaldehyde fixed and paraffin embedded (FFPE). For western blot analysis, frozen tumor samples were sliced into pieces $\sim 1.2 \mathrm{~mm}$ in diameter and transferred into Lysing Matrix type $D$ tubes containing ceramic beads (MP Biomedicals, Santa Ana, CA, USA) in the presence of RIPA buffer (50 mM Tris-HCl, pH=7.4, $150 \mathrm{mM} \mathrm{NaCl}, 2 \mathrm{mM}$ EDTA, $50 \mathrm{mM} \mathrm{NaF}, 0.5 \%$ sodium deoxycholate, $0.1 \%$ SDS, and $1 \%$ NP-40). The samples were lysed with a FastPrep homogenizer (MP Biomedicals; four cycles of $40 \mathrm{~s}$ at $6 \mathrm{~m} / \mathrm{s}$, each followed by a 5 -min pause on ice). The samples were then centrifuged at $20000 \times g$ for $30 \mathrm{~min}$ and proteins in the supernatant were quantified by the BCA Protein Assay (Pierce). Equal amounts of protein were analyzed by western blotting. For IHC, FFPE tissue sections were stained with hematein/eosin/safran and IHC was performed with an antibody against the intracellular domain of Met (SP44 CONFIRM, Ventana Medical Systems). Met expression was scored according to the study of Spigel et al. ${ }^{48}$ (score 3: high-intensity staining of at least $50 \%$ of the tumor; score 2 : moderate staining of at least $50 \%$ of the tumor and high-intensity staining of $<50 \%$; score 1 : weak staining of at least $50 \%$ of the tumor and moderate or strong staining of $<50 \%$; score 0 : no staining or staining at any intensity of $<50 \%$ of the tumor).

\section{Conflict of Interest}

The authors declare no conflict of interest.

Acknowledgements. This work was supported by the CNRS, the Pasteur Institute of Lille, and INSERM, and by grants from the Ligue Contre le Cancer, Comité Nord, the Association pour la Recherche sur le Cancer, the Institut National du Cancer, the Cancéropôle Nord-Ouest, the Site de Recherche Intégrée sur le Cancer, 
SIRIC ONCOLille, and the Roche company. We thank the Microscopy Imaging Cytometry Facility of the Biolmaging Center Lille Nord-de-France for access to instruments and technical advice, and the Chemistry Systems Biology facility for its technical advice and support.

1. Trusolino L, Bertotti A, Comoglio PM. MET signalling: principles and functions in development, organ regeneration and cancer. Nat Rev Mol Cell Biol 2010; 11: 834-848.

2. Bussolino F, Di Renzo MF, Ziche M, Bocchietto E, Olivero M, Naldini L et al. Hepatocyte growth factor is a potent angiogenic factor which stimulates endothelial cell motility and growth. J Cell Biol 1992; 119: 629-641.

3. Maina F, Klein R. Hepatocyte growth factor, a versatile signal for developing neurons. Nat Neurosci 1999; 2: 213-217.

4. Uehara Y, Minowa O, Mori C, Shiota K, Kuno J, Noda T et al. Placental defect and embryonic lethality in mice lacking hepatocyte growth factor/scatter factor. Nature 1995; $\mathbf{3 7 3}$ 702-705.

5. Schmidt C, Bladt F, Goedecke S, Brinkmann V, Zschiesche W, Sharpe M et al. Scatter factor/hepatocyte growth factor is essential for liver development. Nature 1995; 373 699-702.

6. Bladt F, Riethmacher D, Isenmann S, Aguzzi A, Birchmeier C. Essential role for the c-met receptor in the migration of myogenic precursor cells into the limb bud. Nature 1995; 376: 768-771.

7. Maina F, Hilton MC, Ponzetto $C$, Davies AM, Klein R. Met receptor signaling is required for sensory nerve development and HGF promotes axonal growth and survival of sensory neurons. Genes Dev 1997; 11: 3341-3350.

8. Calvi C, Podowski M, Lopez-Mercado A, Metzger S, Misono K, Malinina A et al. Hepatocyte growth factor, a determinant of airspace homeostasis in the murine lung. PLoS Genet 2013; 9: e1003228.

9. Huh C-G, Factor VM, Sánchez A, Uchida K, Conner EA, Thorgeirsson SS. Hepatocyte growth factor/c-met signaling pathway is required for efficient liver regeneration and repair. Proc Natl Acad Sci USA 2004; 101: 4477-4482.

10. Phaneuf D, Moscioni AD, LeClair C, Raper SE, Wilson JM. Generation of a mouse expressing a conditional knockout of the hepatocyte growth factor gene: demonstration of impaired liver regeneration. DNA Cell Biol 2004; 23: 592-603.

11. Chmielowiec J, Borowiak M, Morkel M, Stradal T, Munz B, Werner S et al. c-Met is essential for wound healing in the skin. J Cell Biol 2007; 177: 151-162.

12. Ma H, Saenko M, Opuko A, Togawa A, Soda K, Marlier A et al. Deletion of the Met receptor in the collecting duct decreases renal repair following ureteral obstruction. Kidney Int 2009; 76: 868-876

13. Song $Y$, Su M, Panchatsharam $P$, Rood D, Lai L. c-Met signaling is required for efficient postnatal thymic regeneration and repair. Immunology 2014; 144: 245-253.

14. Furlan A, Kherrouche Z, Montagne R, Copin M-C, Tulasne D. Thirty years of research on met receptor to move a biomarker from bench to bedside. Cancer Res 2014; 74: 6737-6744.

15. Jeffers M, Schmidt L, Nakaigawa N, Webb CP, Weirich G, Kishida T et al. Activating mutations for the met tyrosine kinase receptor in human cancer. Proc Natl Acad Sci USA 1997; 94: 11445-11450.

16. Gherardi E, Birchmeier W, Birchmeier C, Vande Woude G. Targeting MET in cancer: rationale and progress. Nat Rev Cancer 2012; 12: 89-103.

17. Scagliotti GV, Novello S, von Pawel J. The emerging role of MET/HGF inhibitors in oncology. Cancer Treat Rev 2013; 39: 793-801.

18. Foveau B, Ancot F, Leroy C, Petrelli A, Reiss K, Vingtdeux V et al. Down-regulation of the me receptor tyrosine kinase by presenilin-dependent regulated intramembrane proteolysis. Mol Biol Cell 2009; 20: 2495-2507.

19. Ancot F, Leroy C, Muharram G, Lefebvre J, Vicogne J, Lemiere A et al. Shedding-generated Met receptor fragments can be routed to either the proteasomal or the lysosomal degradation pathway. Traffic 2012; 13: 1261-1272

20. Schelter F, Kobuch J, Moss ML, Becherer JD, Comoglio PM, Boccaccio C et al. A disintegrin and metalloproteinase-10 (ADAM-10) mediates DN30 antibody-induced shedding of the met surface receptor. J Biol Chem 2010; 285: 26335-26340.

21. Tulasne D, Deheuninck J, Lourenco FC, Lamballe F, Ji Z, Leroy C et al. Proapoptotic function of the MET tyrosine kinase receptor through caspase cleavage. Mol Cell Biol 2004; 24 10328-10339.

22. Foveau B, Leroy C, Ancot F, Deheuninck J, Ji Z, Fafeur V et al. Amplification of apoptosis through sequential caspase cleavage of the MET tyrosine kinase receptor. Cell Death Differ 2006; 14: 752-764.

23. Lefebvre J, Muharram G, Leroy C, Kherrouche Z, Montagne R, Ichim G et al. Caspasegenerated fragment of the Met receptor favors apoptosis via the intrinsic pathway independently of its tyrosine kinase activity. Cell Death Dis 2013; 4: e871.

24. Goldschneider D, Mehlen P. Dependence receptors: a new paradigm in cell signaling and cancer therapy. Oncogene 2010; 29: 1865-1882.

25. Kroemer G, Galluzzi L, Vandenabeele P, Abrams J, Alnemri ES, Baehrecke EH et al Classification of cell death: recommendations of the Nomenclature Committee on Cell Death 2009. Cell Death Differ 2008; 16: 3-11.
26. Halestrap AP. A pore way to die: the role of mitochondria in reperfusion injury and cardioprotection. Biochem Soc Trans 2010; 38: 841-860.

27. Francis RJ, Kotecha S, Hallett MB. Ca2+ activation of cytosolic calpain induces the transition from apoptosis to necrosis in neutrophils with externalized phosphatidylserine. J Leukoc Biol 2013; 93: 95-100.

28. Yun B, Lee H, Ghosh M, Cravatt BF, Hsu K-L, Bonventre JV et al. Serine hydrolase inhibitors block necrotic cell death by preventing calcium overload of the mitochondria and permeability transition pore formation. J Biol Chem 2014; 289: 1491-1504.

29. Billger M, Wallin M, Karlsson JO. Proteolysis of tubulin and microtubule-associated proteins 1 and 2 by calpain I and II. Difference in sensitivity of assembled and disassembled microtubules. Cell Calcium 1988; 9: 33-44.

30. Czogalla A, Sikorski AF. Spectrin and calpain: a 'target' and a 'sniper' in the pathology of neuronal cells. Cell Mol Life Sci 2005; 62: 1913-1924.

31. Kelly BL, Vassar R, Ferreira A. Beta-amyloid-induced dynamin 1 depletion in hippocampa neurons. A potential mechanism for early cognitive decline in Alzheimer disease. J Biol Chem 2005; 280: 31746-31753.

32. Hanahan D, Weinberg RA. Hallmarks of cancer: the next generation. Cell 2011; 144: 646-674.

33. Janssen K, Horn S, Niemann MT, Daniel PT, Schulze-Osthoff K, Fischer U. Inhibition of the ER Ca2+ pump forces multidrug-resistant cells deficient in Bak and Bax into necrosis. J Cell Sci 2009; 122: 4481-4491.

34. Verspurten J, Gevaert K, Declercq W, Vandenabeele P. SitePredicting the cleavage of proteinase substrates. Trends Biochem Sci 2009; 34: 319-323.

35. duVerle D, Takigawa I, Ono Y, Sorimachi H, Mamitsuka H. CaMPDB: a resource for calpain and modulatory proteolysis. Genome Inform Int Conf Genome Inform 2010; 22: 202-213.

36. Duchen MR. Mitochondria, calcium-dependent neuronal death and neurodegenerative disease. Pflüg Arch Eur J Physiol 2012; 464: 111-121.

37. Suzuki K, Tsuji S, Kubota S, Kimura Y, Imahori K. Limited autolysis of Ca2+-activated neutral protease (CANP) changes its sensitivity to Ca2+ ions. J Biochem (Tokyo) 1981; 90: 275-278.

38. Imajoh S, Kawasaki H, Suzuki K. Limited autolysis of calcium-activated neutral protease (CANP): reduction of the Ca2+-requirement is due to the $\mathrm{NH} 2$-terminal processing of the large subunit. J Biochem (Tokyo) 1986; 100: 633-642.

39. Kong-Beltran M, Stamos J, Wickramasinghe $D$. The Sema domain of Met is necessary for receptor dimerization and activation. Cancer Cell 2004; 6: 75-84.

40. Michieli P, Mazzone M, Basilico C, Cavassa S, Sottile A, Naldini L et al. Targeting the tumor and its microenvironment by a dual-function decoy Met receptor. Cancer Cell 2004; 6: 61-73.

41. Coxon A, Rex K, Meyer S, Sun J, Sun J, Chen $Q$ et al. Soluble c-Met receptors inhibit phosphorylation of c-Met and growth of hepatocyte growth factor: c-Met-dependent tumors in animal models. Mol Cancer Ther 2009; 8: 1119-1125.

42. Deheuninck J, Foveau B, Goormachtigh G, Leroy C, Ji Z, Tulasne D et al. Caspase cleavage of the MET receptor generates an HGF interfering fragment. Biochem Biophys Res Commun 2008; 367: 573-577.

43. Arroba Al, Wallace D, Mackey A, de la Rosa EJ, Cotter TG. IGF-I maintains calpastatin expression and attenuates apoptosis in several models of photoreceptor cell death. Eur J Neurosci 2009; 30: 975-986

44. Tulasne D, Foveau B. The shadow of death on the MET tyrosine kinase receptor. Cell Death Differ 2008; 15: 427-434.

45. Matteucci E, Bendinelli P, Desiderio MA. Nuclear localization of active HGF receptor Met in aggressive MDA-MB231 breast carcinoma cells. Carcinogenesis 2009; 30: 937-945.

46. Levallet G, Vaisse-Lesteven M, Le Stang N, Ilg AGS, Brochard P, Astoul P et al. Plasma cell membrane localization of $\mathrm{C}-\mathrm{MET}$ predicts longer survival in patients with malignant mesothelioma: a series of 157 cases from the MESOPATH Group. J Thorac Oncol Off Publ Int Assoc Study Lung Cancer 2012; 7: 599-606.

47. Paumelle R, Tulasne D, Leroy C, Coll J, Vandenbunder B, Fafeur V. Sequential activation of ERK and repression of JNK by scatter factor/hepatocyte growth factor in madin-darby canine kidney epithelial cells. Mol Biol Cell 2000; 11: 3751-3763.

48. Spigel DR, Ervin TJ, Ramlau RA, Daniel DB, Goldschmidt JH, Blumenschein GR et al. Randomized phase II trial of Onartuzumab in combination with erlotinib in patients with advanced non-small-cell lung cancer. J Clin Oncol Off J Am Soc Clin Oncol 2013; 31: 4105-4114.

Cell Death and Disease is an open-access journal published by Nature Publishing Group. This work is licensed under a Creative Commons Attribution 4.0 International License. The images or other third party material in this article are included in the article's Creative Commons license, unless indicated otherwise in the credit line; if the material is not included under the Creative Commons license, users will need to obtain permission from the license holder to reproduce the material. To view a copy of this license, visit http://creativecommons.org/licenses/by/4.0/ 